\title{
Optimizing Production of Mentha longifolia Essential Oil Emulsion Loaded with Omega 3 Fatty Acids by Nano-Fiber/Gas Chromatography
}

\author{
Nasrin Faraji, Sajad Pirsa*, Mohammad Alizadeh and Hadi Almasi
}

Department of Food Science and Technology, Faculty of Agriculture, Urmia University, Urmia, Iran

\begin{abstract}
The main aim of this study is providing of Mentha longifolia L essential oil emulsion loaded with omega 3 fatty acids and optimization by polyaniline (PANI) nano-fiber/gas chromatography (PANI-F/GC). The head space solid phase microextraction (HS-SPME) method by polyaniline nanofibers was used to extract released essential oils of emulsion. The effects of four factors, including omega 3 percent, surfactant-to-oil ratio (SOR\%), surfactant type (TWEEN 20, 80 and caseinate sodium) and storage time on the encapsulation efficiency, and essential oil chromatographic characteristics including total peak number, total peak area and total peak height were studied. The Central Composite Design (CCD) was used to design experiments and study the effects of four factors on the responses and P-value of $<0.05$ was considered statistically significant. Desirability function (D) was used for determination of optimum condition. Results showed that all four factors affected GC profile, essential oil release and encapsulation efficiency. According to the results the emulsion has the best release power on the condition: Omega 3 (\%); 25, Storage Time (day); 60, SOR (\%); 193.33 and Surfactant type; T80 where the total peak number was 3 total peak area: 407 , total peak height: 77 and encapsulation efficiency was $75 \%$.
\end{abstract}

Keywords: Mentha longifolia L; Essential oil; Omega 3 fatty acids; Emulsion; Nano-fiber; Gas chromatography

\section{Introduction}

An emulsion is defined as a mixture of two or more liquids that are unmixable or unblendable. Emulsions are part of a more general class of two-phase systems of matter called colloids [1,2]. Oil and water are the most liquids that are used to form emulsions in the food and pharmaceutical industry. Two types of emulsion are commonly used. Oil/Water $(\mathrm{O} / \mathrm{W})$ emulsion is formed by dispersing of oil phase in the water phase, but Water/Oil (W/O) emulsion is formed by dispersing of water phase in the oil phase. Conventional emulsions, nano-emulsions, or micro-emulsions are types of emulsions that are categorized based on their particle diameter and thermodynamic stability [1,2]. The emulsions with mean droplet diameters $<200 \mathrm{~nm}$ have been defined as nano-emulsions [3,4]. The small particle size of nano-emulsions can lead to good kinetic stability and delivery systems with high optical clarity, so these nano particles are suitable candidates for using in pharmaceutical industries, supplement and food products $[3,4]$. There are two common methods for providing emulsions, including low energy and high energy method. In the high energy method some instrument and techniques like microfluidizers, high-pressure homogenizers and sonicators are used. These techniques rely on specialized equipment to disrupt and intermingle the oil and water phases. The high energy methods can form small droplets of emulsions [5,6]. Omega-3 fatty acids are important for normal metabolism in the human body. Mammals are unable to synthesize omega-3 fatty acids, so using of foods, including omega-3 is necessary for human health. Now days the food industry is trying to provide and develop new functional foods contain omega- 3 fatty acid. Functional foods enriched with omega- 3 provide health benefits above their basic nutritional aspects. Some Omega-3 enriched foods like beverages are quite popular, and there are large areas of growth for omega-3 products in countries with both small and large existing omega-3 markets [7-9].

Encapsulation is a useful method for protection, facilitating the use and preserving of some food materials and food ingredients that are sensitive. In fact, by encapsulation method the sensitive ingredients of food are covered and are protected from undesirable reaction like oxidation. Encapsulation can also mask undesirable flavors or odors, control the release rate and location of a compound, and impact bioavailability of the encapsulated material. Hydrophobic liquid containing volatile aroma compounds of plants is called essential oil. Essential oils are also known as volatile oils, ethereal oils, or simply as the oil of the plant from which they were extracted, such as oil of Mentha longifolia. These oils have some interesting properties like antioxidant, antimicrobial, antifungal, and insecticidal. Essential oils can be used to further decrease the particle size of emulsions. A variety of oils can be used, including medium chain triglyceride oil, citrus oils, and herb oils [10].

Mentha longifolia plant has some benefit properties like digestive, antispasmodic, and carminative that in Iran is used as a stomach pain relieving agent in traditional medicine. The essential oils of Aerial part of the Mentha longifolia have medicinal effects. The Mentha longifolia essential oils have antimicrobial, antioxidant, anti-inflammatory, and fungicidal activity that was reported in the previous works. The essential oil content of this medicinal plant is depending on the climatic and geographical factors [11,12].

Solid-phase microextraction (SPME) is a solid phase extraction sampling technique that involves the use of a fiber coated with an extracting phase, that can be a liquid (polymer) or a solid (Sorbent), which extracts different kinds of analytes (including both volatile and non-volatile) from different kinds of media, that can be in liquid phase like water and wastewater samples, food samples and so, or gas phase.

*Corresponding author: Pirsa S, Department of Food Science and Technology, Faculty of Agriculture, Urmia University, Urmia, Iran, Tel: +989145454914; E-mail: pirsa7@gmail.com

Received January 05, 2018; Accepted February 20, 2018; Published February 28, 2018

Citation: Faraji N, Pirsa S, Alizadeh M, Almasi H (2018) Optimizing Production of Mentha Iongifolia Essential Oil Emulsion Loaded with Omega 3 Fatty Acids by Nano-Fiber/Gas Chromatography. J Bioanal Biomed 10: 30-39. doi:10.4172/1948-593X.1000201

Copyright: (c) 2018 Faraji N, et al. This is an open-access article distributed under the terms of the Creative Commons Attribution License, which permits unrestricted use, distribution, and reproduction in any medium, provided the original author and source are credited. 
The quantity of analyte extracted by the fibre is proportional to its concentration in the sample as long as equilibrium is reached or, in case of short time pre-equilibrium, with help of convection or agitation [13].

In this work, new emulsion based on Mentha longifolia essential oil loaded with omega- 3 fatty acids was provided. The effects of omega 3 percent, surfactant-to-oil ratio (SOR\%), surfactant type (TWEEN 20,80 and caseinate sodium) and storage time on the encapsulation efficiency and gas chromatography characteristic were studied. The gas chromatography characteristics, including total peak number, total peak area and total peak height were used to study essential oil release from an emulsion. The optimum condition of emulsion production function was obtained based on desirability function.

\section{Experimental}

\section{Reagents and chemicals}

Fish oil was kindly donated by a zahravi company (Perimondo, New York, NY, USA). Tween 80 and 20 (Sigma- Aldrich, St. Louis, MO, USA) caseinate sodium (5.2 $\mathrm{wt} \%$ moisture, $0.05 \mathrm{wt} \%$ calcium) were obtained from Demelkindustrie (Veghel, The Netherlands). Distilled and deionized water obtained from a water purification system (Milli-Q, Millipore, Darmstadt, Germany) was used to prepare all emulsions. All other chemicals used in this study were purchased from either Sigma-Aldrich (St. Louis, MO)

Mentha longifolia oil (penny royal oil) was kindly donated by the magnolia company (Iran). The supplier reported the chemical composition as determined by gas chromatography-mass spectroscopy instrument (GCMS-QP2010 SE, GAS, SHIMADZU, Japan).

\section{Emulsion preparation}

Emulsions were prepared by spontaneous emulsification (according to the reported process) by titrating an organic phase into an aqueous phase [14]. The organic phase consisted of a mixture of fish oil and essential oil (menthe longifolia essential oil) and types of surfactants (tween 20, 80, caseinate sodium) by varying the surfactant-to-oil ratio (SOR) (according to the Table 1) were first mixed together for $15 \mathrm{~min}$ at $25^{\circ} \mathrm{C}$ and then the mixture was slowly poured into aqueous phase for 8 hours with continuous stirring at $800 \mathrm{rpm}$.

A set of standard conditions was used to prepare the emulsions: composition $=20 \% \mathrm{wt}$ oil, and $80 \mathrm{wt} \%$ deionized water. Nevertheless, a number of parameters were systematically varied to determine their influences on the emulsion formation $[15,16]$. Four main variables were tested (according to the Table 1): surfactant-to-oil ratio, surfactant type, storage time, and fish oil concentration. A series of non-ionic surfactants (TWEEN 20, 80, 20:80 and caseinate sodium) was tested to establish the influence of surfactant type on emulsion formation. The standard conditions mentioned above were utilized to prepare the emulsions in these experiments using fish oil. The surfactant-to-oil ratio was varied to determine the most suitable surfactant concentration to prepare the emulsions. The total oil content was fixed at $20 \mathrm{wt} \%$, while the surfactant-to-oil ratio was varied according to the Table 1 and the following equation:

$$
\mathrm{SOR}=\mathrm{M}_{\mathrm{S}} / \mathrm{M}_{\mathrm{o}} \times 100
$$

Where, $M_{s}$ and $M_{o}$ are the masses of the surfactant and oil respectively. The influence of time during storage was determined by varying the time (0-60 days).

\begin{tabular}{|c|c|c|c|c|}
\hline \multirow[b]{2}{*}{ Run order } & \multicolumn{4}{|c|}{ Factors } \\
\hline & $\begin{array}{c}\text { A: Omega } 3 \\
(\%)\end{array}$ & $\begin{array}{l}\text { B: Storage } \\
\text { Time (day) }\end{array}$ & C: SOR (\%) & $\begin{array}{c}\text { D: Surfactant } \\
\text { type }\end{array}$ \\
\hline 1 & 75 & 24.6 & 300 & SC \\
\hline 2 & 52.75 & 9.2 & 91 & $\mathrm{~T} 80$ \\
\hline 3 & 50 & 38.1 & 155 & T20 \\
\hline 4 & 65 & 1.0 & 10 & SC \\
\hline 5 & 50 & 38.1 & 155 & T20 \\
\hline 6 & 75 & 60.0 & 300 & $\mathrm{~T} 80$ \\
\hline 7 & 25 & 60.0 & 276 & T80:20 \\
\hline 8 & 75 & 30.5 & 10 & $\mathrm{~T} 80$ \\
\hline 9 & 25 & 60.0 & 10 & $\mathrm{~T} 80$ \\
\hline 10 & 75 & 60.0 & 68 & SC \\
\hline 11 & 25 & 1.0 & 10 & T20 \\
\hline 12 & 75 & 1.0 & 134 & T80:20 \\
\hline 13 & 52.75 & 9.2 & 91 & $\mathrm{~T} 80$ \\
\hline 14 & 25 & 1.0 & 10 & T80 \\
\hline 15 & 25 & 36.4 & 10 & SC \\
\hline 16 & 75 & 1.0 & 300 & T80 \\
\hline 17 & 71.25 & 60.0 & 10 & T80:20 \\
\hline 18 & 25 & 30.5 & 300 & T80 \\
\hline 19 & 25 & 1.0 & 242 & SC \\
\hline 20 & 25 & 1.0 & 10 & T80:20 \\
\hline 21 & 71.75 & 37.8 & 161 & T80:20 \\
\hline 22 & 25 & 60.0 & 300 & T20 \\
\hline 23 & 43.60 & 58.8 & 10 & T20 \\
\hline 24 & 25 & 1.0 & 10 & T80:20 \\
\hline 25 & 75 & 60.0 & 10 & T20 \\
\hline 26 & 50 & 38.1 & 155 & T20 \\
\hline 27 & 40.95 & 1.0 & 174 & T20 \\
\hline 28 & 75 & 1.0 & 300 & T20 \\
\hline 29 & 25 & 30.5 & 300 & T80 \\
\hline 30 & 47 & 1.0 & 300 & T80:20 \\
\hline 31 & 56.07 & 54.1 & 300 & T80:20 \\
\hline 32 & 35.25 & 60.0 & 300 & SC \\
\hline
\end{tabular}

Table 1: List of experiments in the CCD.

\section{Analysis methods}

Encapsulation efficiency: Total oil and free oil should be calculated for calculation of encapsulation efficiency so the following processes were done:

a) Extraction of free oil: Extraction of the free oil was made with petroleum ether (b.p.60-90 $\mathrm{C}$ ) following the method as described by Anna Millqvist-Fureby $[17,18]$, which was modified to suit the sample volume. One gram of emulsion was added to $10 \mathrm{ml}$ dried petroleum ether, and shaken for $2 \mathrm{~min}$. The solvent was then separated by filtration. The solid residue was washed two times in $2 \mathrm{ml}$ petroleum ether. The combined filtrate was evaporated using a rotary evaporator. Fat residue was then dried at $105^{\circ} \mathrm{C}$ until a constant weight was reached.

b) Extraction of total oil: The extraction of total oil was based on the method of Utai Klinkesorn et al. with some modification [19]. Fivemilliliters of distilled water $\left(60^{\circ} \mathrm{C}\right)$ were added to $0.5 \mathrm{~g}$ emulsion and shaken for 15 min using thermostat, Water Bath Vibrator (CD3192, Xutemp, Hangzhou, China). The resulting solution was then extracted with $25 \mathrm{ml}$ hexane/isopropanol $(3: 1, \mathrm{v} / \mathrm{v})$. The tubes were then vortexed for $15 \mathrm{~min}$, and centrifuged for another $15 \mathrm{~min}$ at $8000 \times \mathrm{g}$. The clear organic phase was collected while the aqueous phase was re-extracted 
with the solvent mixture [20,21]. After filtration through anhydrous $\mathrm{Na}_{2} \mathrm{SO}_{4}$, the solvent was evaporated in a rotary evaporator (RE-52AA, Shanghai Biochemical Instrument Company, China) at $70^{\circ} \mathrm{C}$. The solvent-free extract was dried at $105^{\circ} \mathrm{C}$. The amount of encapsulated oil was determined gravimetrically Microencapsulation efficiency (MEE)

The encapsulation efficiency (EE) was calculated as follows:

$$
\text { EE }(\%)=\frac{\text { Total oil }- \text { Free oil }}{\text { Total oil }} \times 100
$$

Chromatographic Conditions: A gas chromatography instrument (Agilent 7890 A, Wilmington, DE, USA) with flame ionization detector (GC-FID) at the following condition was used for separation, detection, and analysis of released essential oils: capillary column, silica, $30 \mathrm{~m}$ length, $0.25 \mu \mathrm{m}$ phase thickness and $320 \mu \mathrm{m}$ i.d; $\mathrm{N}_{2}$ used as carrier gas with a flow rate of $2 \mathrm{ml} / \mathrm{min}$; the column pressure was set at 8.8913 psi. Splitless mode injection was $50 \mathrm{ml} / \mathrm{min}$ splitting ratio in $0.75 \mathrm{~min}$. The initial column temperature was $50^{\circ} \mathrm{C}$ and then the temperature was increased to $80^{\circ} \mathrm{C}$ at the $2^{\circ} \mathrm{C} / \mathrm{min}$ and kept in $80^{\circ} \mathrm{C}$ for $5 \mathrm{~min}$. The detector temperature was $250^{\circ} \mathrm{C}$. Heater temperature $200^{\circ} \mathrm{C}, \mathrm{H}_{2}$ flow 27 $\mathrm{mL} / \mathrm{min}$ and air flow $20 \mathrm{ml} / \mathrm{min}[23,24]$.

Headspace extraction procedure: The PANI fiber was synthesized by chemical polymerization on the polyester at room temperature according to the our previous work [22]. HS-SPME extraction procedure was done like previously reported works [23,24].

The emulsion sample $(2 \mathrm{ml})$ was extracted with PANI fiber using headspace solid phase microextraction (HS-SPME). PANI fiber connected to the needle of designed syringe was used. To the condition of provided PANI fiber, it was injected into GC injection port for $1 \mathrm{~h}$ at $100^{\circ} \mathrm{C}$ prior to use. A glass $(10 \mathrm{ml})$ with a polytetrafluoroethylene silicon septum containing a magnetic stir bar and $2 \mathrm{ml}$ of emulsion sample was provided. An aluminium cap was used to seal the vial to prevent sample loss due to evaporation. A hot plate was used to heat vials contained some emulsion samples during the extraction process. When the stirring liquid sample $(600 \mathrm{rpm})$ in the sealed vial is heated on the hotplate, the PANI fiber by designing syringe was exposed to the headspace of it. After completing of extraction of the analyte to PANI fiber, the fiber was withdrawn into the designed syringe needle and removed from the vial, then immediately inserted into the injection port of the GC $[23,24]$. Some parameters that affect extraction efficiency like, extraction time $(20 \mathrm{~min})$ and temperature $\left(80^{\circ} \mathrm{C}\right)$ were optimized experimentally. The chromatographic separation is shown in Figure 1.

Statistical analysis: Response surface method (RSM) was used to study the effects of the independent variables, including omega 3 (A), storage time (B), SOR\% (C) and type of surfactant (D). The experiments were designed according to the central composite design (CCD). Thirty two Runs were formed. In Table 1, the 4 processing variables as factors, levels and experimental design are given. Statistical analysis was performed through subjection on the data for analysis of variance (ANOVA) using commercial statistics software (Design Expert-7). Multiple range test and Polynomial equations $(p \leq 0.05)$ was used to detect different factors effect on the emulsion properties.

\section{Results and Discussion}

\section{Morphology}

The morphology of P-ANI synthesized on the surface of polyester fiber analyzed by scanning electron microscopy. Figure 2 shows the morphology of P-ANI coated on the surface of polyester fiber. The shape of the particles is typically seed like $(\approx 50-130 \mathrm{~nm})$.

\section{Design expert and polynomial equations}

Table 2 presents the evaluated responses for each run in Table 1 including, total peak number, total peak area, total peak height and

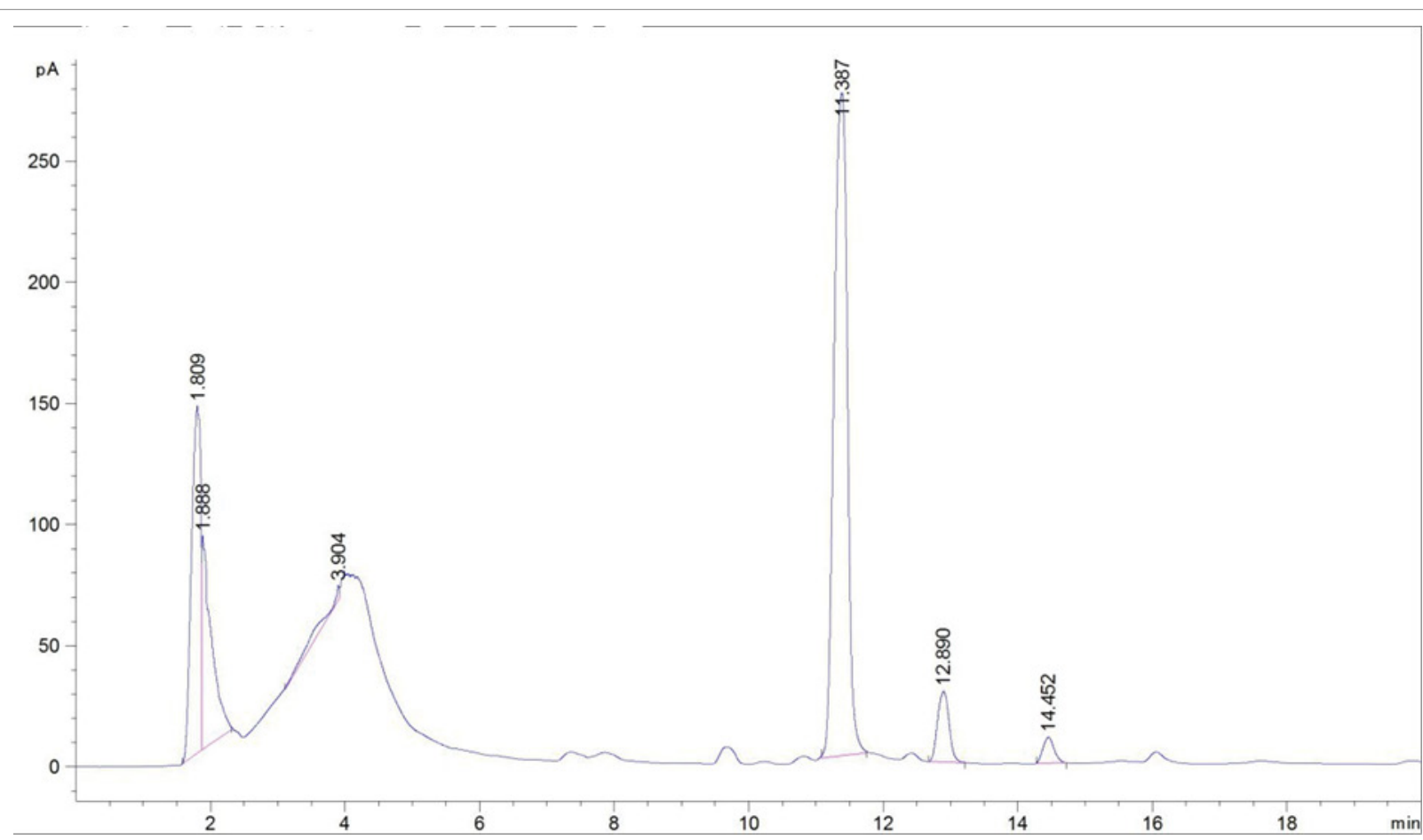

Figure 1: GC-FID chromatogram for volatile organic compounds of emulsion extracted by PANI fiber. 


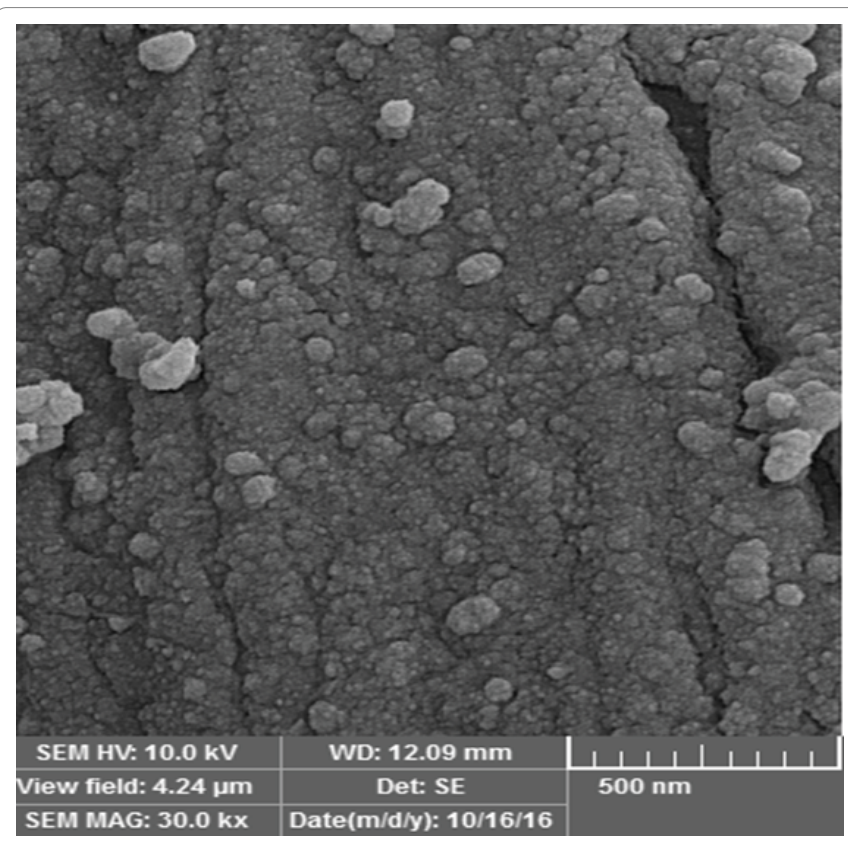

Figure 2: Morphology of P-ANI synthesized on the surface of polyester fiber.

encapsulation efficiency. The Design-Expert software (version 7) was used to perform statistical analysis. Initially, the full term second order polynomial response surface models were fitted to each of the response variables, according to the following equation:

$$
Y=\beta_{0}+\sum_{i=1}^{3} \beta_{i} x_{i}+\sum_{i=1}^{3} \sum_{j=i+1}^{3} \beta_{i j} x_{i} x_{j}+\sum_{i=1}^{3} \beta_{i j} x_{i i}^{2}
$$

Where $\mathrm{Y}$ is the responses (total peak number, total peak area, total neak height and encapsulation efficiency); $\mathrm{Xi}$ and $\mathrm{Xj}$ are variables and $\beta$ values are the coefficient values obtained through multiple linear regressions. The quadratic polynomial models for all response functions accompanied by $\mathrm{F}$ values and corresponding $\mathrm{R} 2$ was used, the estimated regression coefficients summarized in Table 3.

\section{Response surface method}

Response Surface Method (RSM) was used to study the effects of four factors on the encapsulation efficiency and chromatographic characteristics of provided emulsions. In this study the contour plots and multi regression plots were used to study factors effects on the responses and interactions of different factors.

Chromatographic responses: The volatile compounds GC profile, including total peak number, total peak area and total peak height were used for studying the effects of four factors, including omega 3 percent, surfactant-to-oil ratio (SOR\%), surfactant type (TWEEN 20, 80 and caseinate sodium) and storage time on the volatile compound releasing from emulsion.

Figure 3 shows interaction curves of total peak number versus omega $3 \%$ in the different type of surfactant at the storage time $(30.5$ day) and SOR (155\%) and total peak number versus SOR\% in the different type of surfactant at the storage time (30.5 day) and omega 3 $(50 \%)$ and total peak number versus storage time in the different type of surfactant at the omega $3(50 \%)$ and SOR (155\%).

According to the Figure 3 increasing of omega 3 from 25 to $75 \%$ in the presence of SC, T20 and T80 slightly increases the total peak

\begin{tabular}{|c|c|c|c|c|}
\hline \multirow{2}{*}{$\begin{array}{l}\text { Run } \\
\text { order }\end{array}$} & \multicolumn{4}{|c|}{ Responses } \\
\hline & $\begin{array}{c}\text { Total peak } \\
\text { number }\end{array}$ & $\begin{array}{c}\text { Total peak } \\
\text { area }\end{array}$ & $\begin{array}{c}\text { Total peak } \\
\text { height }\end{array}$ & $\begin{array}{l}\text { Encapsulation } \\
\text { efficiency }(\%)\end{array}$ \\
\hline 1 & 8 & 820 & 146 & 63.8 \\
\hline 2 & 6 & 235 & 83 & 81.4 \\
\hline 3 & 6 & 295 & 74 & 72 \\
\hline 4 & 10 & 934 & 134 & 55.7 \\
\hline 5 & 5 & 311 & 85 & 81.4 \\
\hline 6 & 8 & 1178 & 91 & 80.4 \\
\hline 7 & 9 & 627 & 141 & 66.0 \\
\hline 8 & 7 & 1367 & 260 & 65.1 \\
\hline 9 & 6 & 1278 & 271 & 72.3 \\
\hline 10 & 11 & 1131 & 96 & 50.2 \\
\hline 11 & 9 & 1087 & 159 & 50.8 \\
\hline 12 & 3 & 201 & 98 & 77.0 \\
\hline 13 & 4 & 315 & 75 & 71.5 \\
\hline 14 & 8 & 340 & 88 & 54.4 \\
\hline 15 & 11 & 1589 & 383 & 59.7 \\
\hline 16 & 5 & 946 & 98 & 85.2 \\
\hline 17 & 13 & 2024 & 269 & 64.5 \\
\hline 18 & 5 & 431 & 124 & 60.5 \\
\hline 19 & 6 & 465 & 102 & 58.8 \\
\hline 20 & 11 & 1378 & 261 & 60.8 \\
\hline 21 & 5 & 341 & 125 & 75.5 \\
\hline 22 & 8 & 379.6 & 84 & 70.7 \\
\hline 23 & 9 & 1260 & 268 & 67.4 \\
\hline 24 & 10 & 1366 & 188 & 71.3 \\
\hline 25 & 11 & 1489 & 248 & 52.5 \\
\hline 26 & 6 & 353 & 90 & 76.0 \\
\hline 27 & 4 & 418 & 42 & 83.5 \\
\hline 28 & 5 & 334 & 67 & 79.1 \\
\hline 29 & 6 & 759 & 155 & 69.4 \\
\hline 30 & 5 & 536 & 102 & 80.0 \\
\hline 31 & 7 & 587 & 111 & 70.4 \\
\hline 32 & 7 & 769 & 234 & 66.3 \\
\hline
\end{tabular}

Table 2: List of responses in the CCD for the each run.

number, but in the presence of T20:80 decreases the total peak number. Increasing of SOR\% from 10 to $160 \%$ decreases the total peak number, but after $160 \%$ to $300 \%$ the total peak number almost is constant for all types of surfactants. The total peak number is increased for all surfactants by increasing of storage time.

The SPME is a method for extraction of volatile compounds from a headspace of sample and considering that encapsulation technique protect bioactive material (essential oil) against chemical and environmental degradation factors, so it is expected that by encapsulation of essential oil and omega-3, the low volatile compound accumulate in the head space of sample. The volatile compounds in the head space are caused by the essential oil and oxidation of the omega- 3 . So decreasing of volatile compound in the head space of samples leads to reduction of total peak number in the gas chromatography [25]. Increasing of storage time cause to release of essential oil to the head space, so the total peak number is increased.

It should be noted that all the emulsions showed a lower peak number in comparison with the control sample (the sample of the essential oil without encapsulation). Dias et al. used the SPME method to investigate the products of oxidation of beta-caryophyllene. They reported that beta-caryophyllene emulsion compared to the beta- 


\begin{tabular}{|c|c|c|}
\hline Response & Regression equation & Model Summary \\
\hline Total peak number & $\begin{array}{l}=5.556955609-0.093711304 \times A+1.025317552 \times B-1.343693072 \times C+1.192336915 \times D_{1}-1.477937133 \times \\
D_{2}-0.179733966 \times D_{3}+0.909056462 \times A B+0.671995845 \times A D_{1}+0.425125788 \times A D_{2}-0.070508785 \times A D_{3} \\
-0.259597245 \times B D_{1}-0.883104921 \times B D_{2}+0.192514328 \times B D_{3}-0.582122122 \times C D_{1}+0.73769481 \times C D_{2} \\
+0.644606816 \times C D_{3}+2.569014589 \times C^{2}\end{array}$ & $\begin{array}{l}R-s q=0.953 \\
R-s q(\text { adj) }=0.895\end{array}$ \\
\hline Total peak area & $\begin{array}{l}=436.4087911-8.093946564 \times A+191.7448448 \times B-349.2842413 \times C+95.21633027 \times D_{1}-41.56635817 \times \\
D_{2}-155.0526183 \times D_{3}-35.02569084 \times A D_{1}+256.8420021 \times D_{2}-87.67357641 \times D_{3}-184.5255613 \times \\
B C+2.871472696 \times D_{1}+111.216313 \times D_{2}-162.0832887 \times B_{3}+46.72043076 \times C D_{1}+229.4298495 \times \\
C D_{2}-58.97056477 \times C D_{3}+549.6992994 \times C^{2}\end{array}$ & $\begin{array}{l}R-s q=0.970 \\
R-s q(\text { adj })=0.933\end{array}$ \\
\hline Total peak height & $\begin{array}{l}\text { Total height }=119.4461879-21.50204977 \times A+28.26674797 \times B-64.76314278 \times C+25.62928665 \times \\
D_{1}-25.20132568 \times D_{2}-26.59405465 \quad \times D_{3}-27.67634566 \times A B-48.2282646 \times A D_{1}+29.26286617 \times A D_{2} \\
+16.57379467 \times A D_{3}-19.62097401 \times B C+28.41806686 \times C D_{1}+15.16039544 \times C D_{2}-21.72498266 \times C D_{3}- \\
53.8909451 \times B^{2}+99.23627192 \times C^{2}\end{array}$ & $\begin{array}{l}R-s q=0.951 \\
R-s q(\text { adj })=0.90\end{array}$ \\
\hline $\begin{array}{l}\text { Encapsulation } \\
\text { Efficiency (\%) }\end{array}$ & $\begin{array}{l}=77.96555489+0.487290136 \times A+0.286941484 \times B+4.299373327 \times C-7.443909122 \times D_{1}+4.265741504 \times D_{2}- \\
0.286371369 \times D_{3}-3.516814174 \times A B+3.67351858 \times A C-2.460457422 \times D_{1}+4.280249425 \times A_{2}-1.170527672 \times \\
A D_{3}-2.605453954 \times B C-0.300114916 \times C D_{1}+0.810430638 \times C D_{2}+4.160500924 \times C D_{3}-8.203480592 \times A^{2}- \\
5.523429726 \times C^{2}\end{array}$ & $\begin{array}{l}\text { R-sq }=0.886 \\
R-s q(\text { adj })=0.75\end{array}$ \\
\hline \multicolumn{3}{|c|}{$A=$ Omega-3 (\%) B=storage time (day) $C=S O R(\%) D=$ Surfactant type (D1=SC, D2=T80, D3=T20, D4=T80:T20) } \\
\hline
\end{tabular}

Table 3: Some characteristics of the constructed models for responses.

caryophyllene control solution had a lower total peak area, indicating the protective effect of the nanocomposite structure against oxidation [26].

Figure 4 shows interaction curves of total peak area versus omega $3 \%$ in the different type of surfactant at the storage time (30.5 day) and SOR (155\%) and total peak area versus SOR\% in the different type of surfactant at the storage time (30.5 day) and omega 3 (50\%) and total peak area versus storage time in the different type of surfactant at the omega 3 (50\%) and SOR (155\%).

According to the results (Figure 4), increasing of omega 3 from 25 to $75 \%$ (in the presence of SC, T20 and T20:80) increases the total peak number, but in the presence of T80 decreases the total peak area. Increasing of SOR\% from 10 to $160 \%$ decreases the total peak area, but after $160 \%$ to $300 \%$ the total peak area is almost constant for all type of surfactants. The total peak area is increased for all surfactants by increasing of storage time.

Increasing the concentration of surfactant increases the absorption of surfactant molecules to the surface of oil/water and decreases surface tension. The decrease in surface tension cause to increase surface motility and superficial disturbances and smaller particles are produced (nanometer) [27]. In the reported works, it had been mentioned that the particle size had the important influence on the volatile compounds protection and big particles can protect the volatile compound lower than small particles [28]. The particle size and encapsulation efficiency were decreased by Increasing of omega-3 percent. In the previous similar works, it has been reported that using of protein compounds for encapsulation of volatile compounds cause to interact between protein and volatile compound and inhibit release of volatile compounds [29].

Encapsulation efficiency: The encapsulation efficiency was used for studying the effects of four factors, including omega 3 percent, surfactant-to-oil ratio (SOR\%), surfactant type (TWEEN 20, 80 and caseinate sodium) and storage time on the nano-encapsulation production.

Figure 5 shows Contour plots of encapsulation efficiency versus omega-3 (\%), SOR (\%) and storage time. According to the Figure 5 and other Contour plots of encapsulation efficiency, increasing of omega 3 from 25 to $62 \%$ in the presence of all types of surfactants increases the encapsulation efficiency but from $62 \%$ to $75 \%$ decreases the encapsulation efficiency. Increasing of SOR\% from 10 to $160 \%$ increases the encapsulation efficiency but from $160 \%$ to $300 \%$ the encapsulation efficiency is decreased for all type of surfactants. The encapsulation efficiency is increased for all surfactants by increasing of storage time.

According to the results T80 has the best encapsulation efficiency. The complete coating of the interlayer section and the connection between the hydrophilic sections of the surfactant with the hydrophobic core cause to protect bioactive material in the emulsion structure, but in the case of sodium caseinate because the caseinate is a heavy molecule, molecules interact together and cannot be packed, and the protein cannot reduce surface tension, so the sodium caseinate has the lowest encapsulation efficiency [30]. Ton and coworkers (2015) in the similar study on the microencapsulation of Rambutan oil loaded with unsaturated fatty acids by sodium caseinate, isolated whey protein and isolated soybean protein reported that the best encapsulation efficiency was obtained by isolated whey Protein and isolated soybean protein and the worst encapsulation efficiency was obtained by sodium caseinate that confirm our results Figure 5 [31]

Relation between encapsulation efficiency and chromatographic responses: Figure 6 shows main affect plot of encapsulation efficiency versus total peak number and total peak height. According to the Figure 6 there are good relations between encapsulation efficiency and the total peak number and total peak height. Results showed that in the chromatographic data, the high encapsulation efficiency showed the low peak area and peak height.

The SPME is a method for extraction of volatile compounds from a headspace of sample and considering that encapsulation technique protect bioactive material (essential oil) against chemical and environmental degradation factors, so it is expected that by encapsulation of essential oil and omega-3, the low volatile compound accumulate in the head space of sample. The volatile compounds in the head space are caused by the essential oil and oxidation of the omega- 3 . So decreasing of volatile compound in the head space of samples leads to the reduction of the total peak number in the gas chromatography.

\section{Combined desirability function analysis}

The combined desirability function (D) is a parameter that calculated by geometric mean and used for estimate the best condition in the experimental analysis that several factors affect the responses. In the combined desirability function $\mathrm{D}$, each response can be assigned an importance relative to the other responses. The following equation is used to compute the combined desirability function: 
Design-Expert@ Sof tware

peak no.

$-\mathrm{D} 1 \mathrm{SC}$
$\Delta \mathrm{D} 2 \mathrm{~T} 80$

$\Delta \mathrm{D} 2$ T 80
D $\mathrm{T} 20$
$\mathrm{D} 4 \mathrm{~T}$ T $80: 20$

X1 $=$ A: Omega $3(\%)$

Actual Factors

B: Storage Time(day $)=30.50$

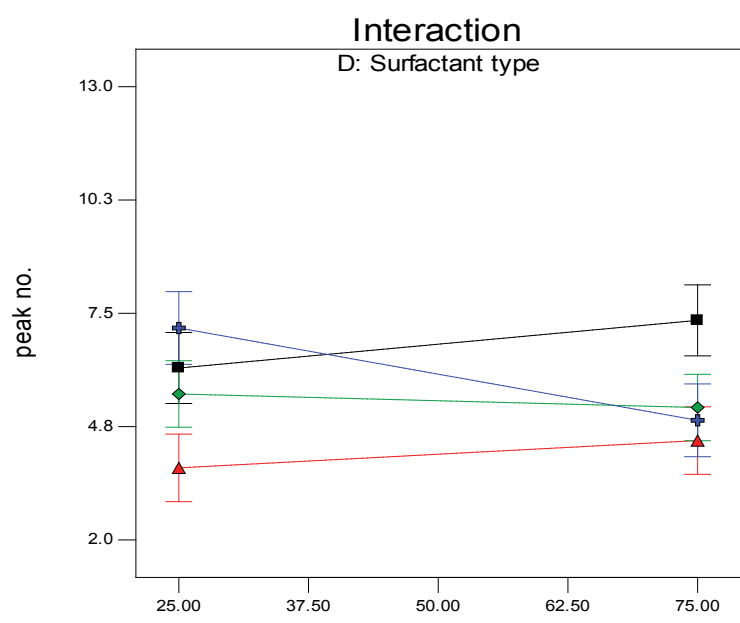

A: Omega 3(\%)

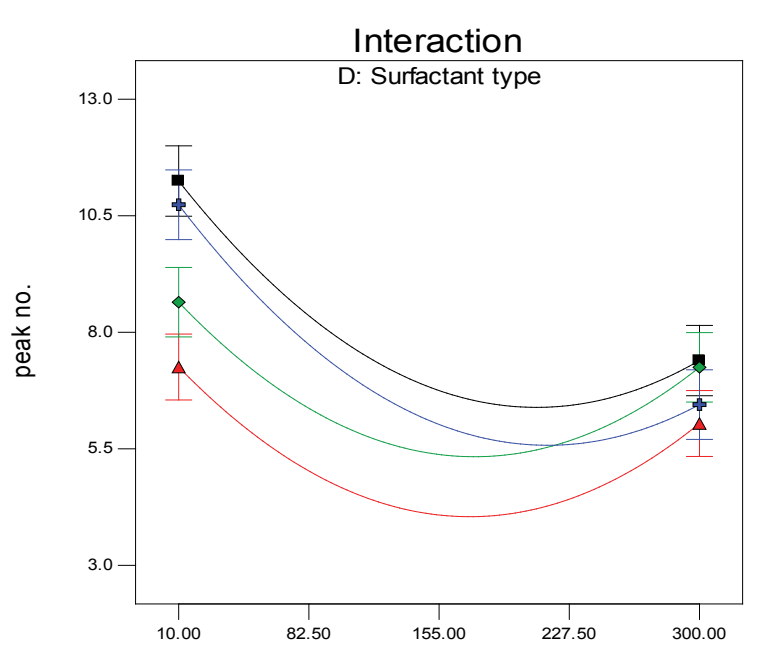

C: $\operatorname{SOR}(\%)$

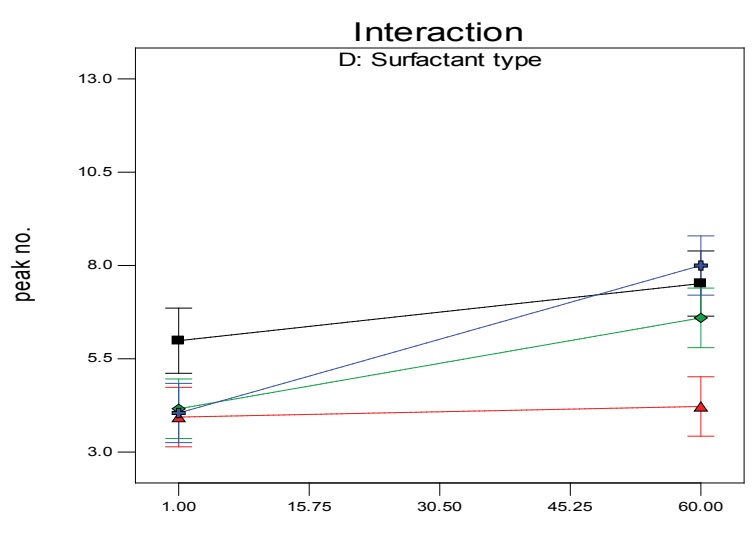

B: Storage Time(day)

Design-Expert® Sof tware

peak no.

- D1 SC
$\Delta$ D2 T80

D 33 T20
- D4 T80:20

$\mathrm{X} 1=\mathrm{C}: \mathrm{SOR}(\%)$
$\mathrm{X} 2=\mathrm{D}:$ Surf actant ty pe

Actual Factors

A: Omega $3(\%)=50.00$
B: Storage Time $($ day $)=30.50$

Design-Expert@ Sof tware

peak no.

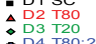

$x_{1}=8:$ Storage Time(day)
$X_{2}=\mathrm{D}$ : Surf actant type

Actual Factors
A: Omega $3(\%)=50.00$
C: $\operatorname{SOR}(\%)=155.00$

Figure 3: Interaction curve of total peak number versus omega3 (\%), SOR (\%) and storage time. 
Design-Expert@ Sof tware

total area

- D1 SC

$\Delta$
$\Delta$

X1 $=$ A: Omega $3(\%)$
X2 $=$ D: Surf actant type

Actual Factors
B: Storage Time(day) $=30.50$
C: $\operatorname{SOR}(\%)=155.00$

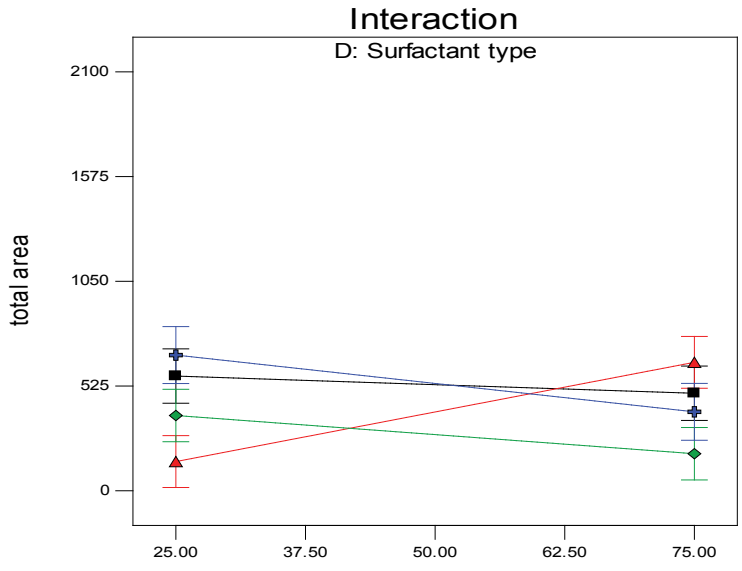

A: Omega 3(\%)

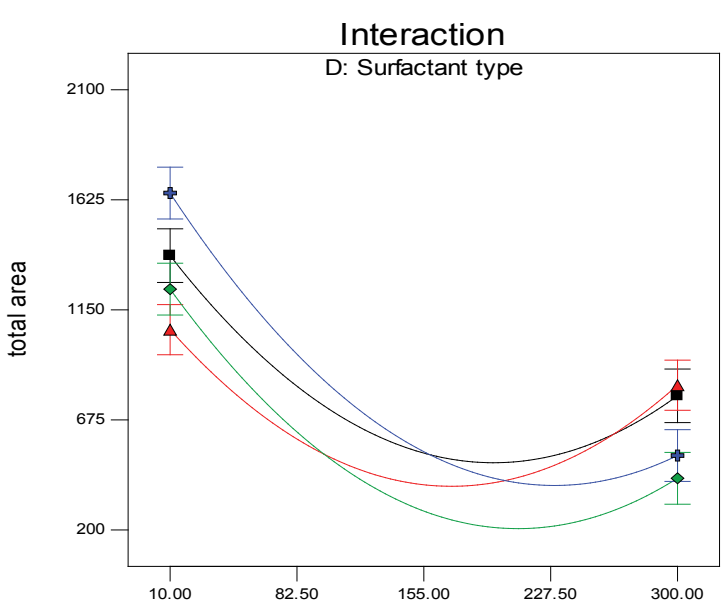

C: $\operatorname{SOR}(\%)$

Design-Expert@ Sof tware

total area

- D1 SC
$\Delta$ D2 T80

- D4 T80:20

$\mathrm{X} 1=\mathrm{C}: \mathrm{SOR}(\%)$
$\mathrm{X}=\mathrm{D}$ : Surfactant ty pe

Actual Factors

A: Omega $3(\%)=50.00$
B: Storage Time $($ day $)=30.50$

Design-Expert@ Sof tware

total area

- D1 SC
$\Delta$ D2 T80
$\bullet$ D 320

D4 T80:20

$X_{1}=$ B: Storage Time(day)
$X_{2}=D$ : Surfactant type

Actual Factors

A: Omega $3(\%)=50.00$
C: $\operatorname{SOR}(\%)=155.00$

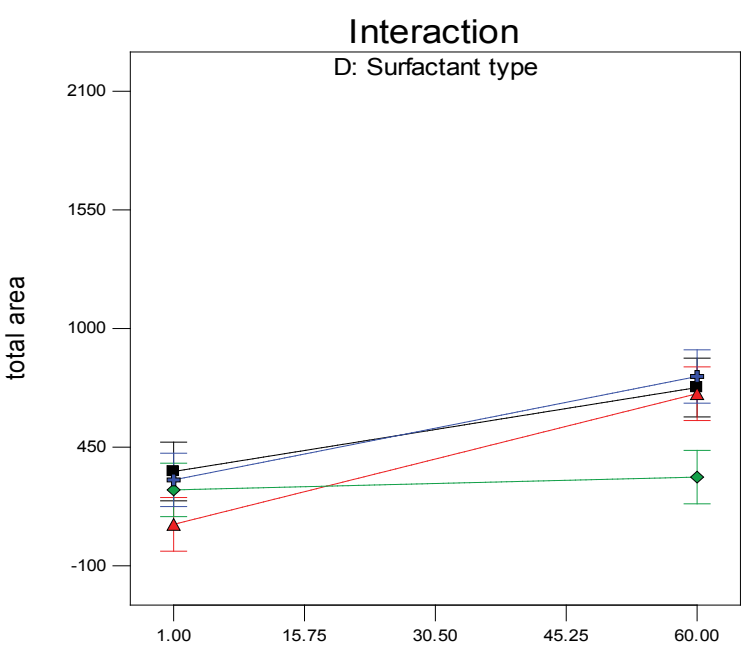

B: Storage Time(day)

Figure 4: Interaction curve of total peak area versus omega-3 (\%), SOR (\%) and storage time. 


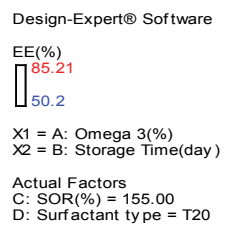
Actual Factors
C: SOR $(\%)=155.00$
D: Surfactant type $=$ T2

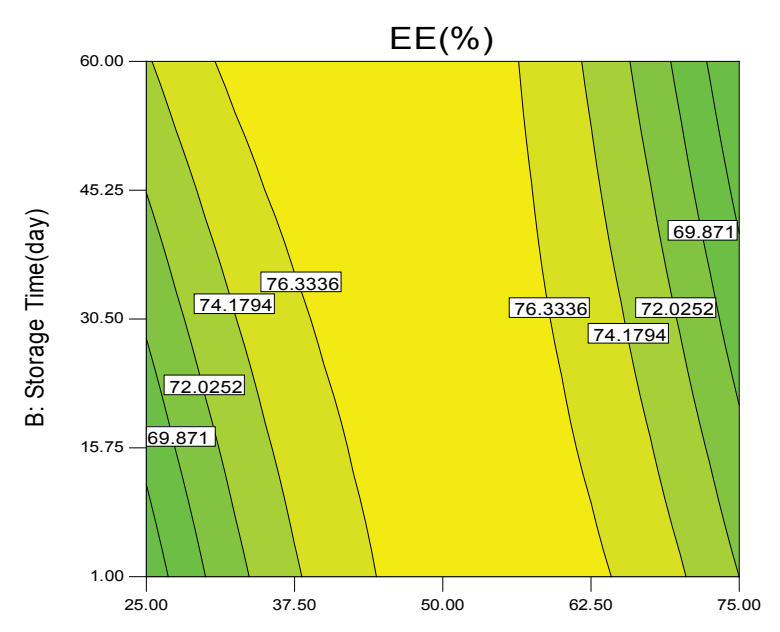

A: Omega 3(\%)

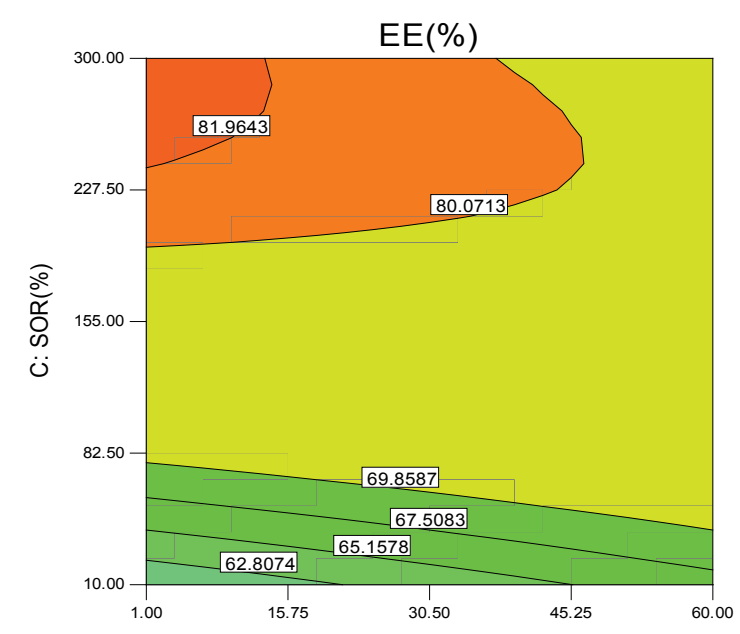

B: Storage Time(day)

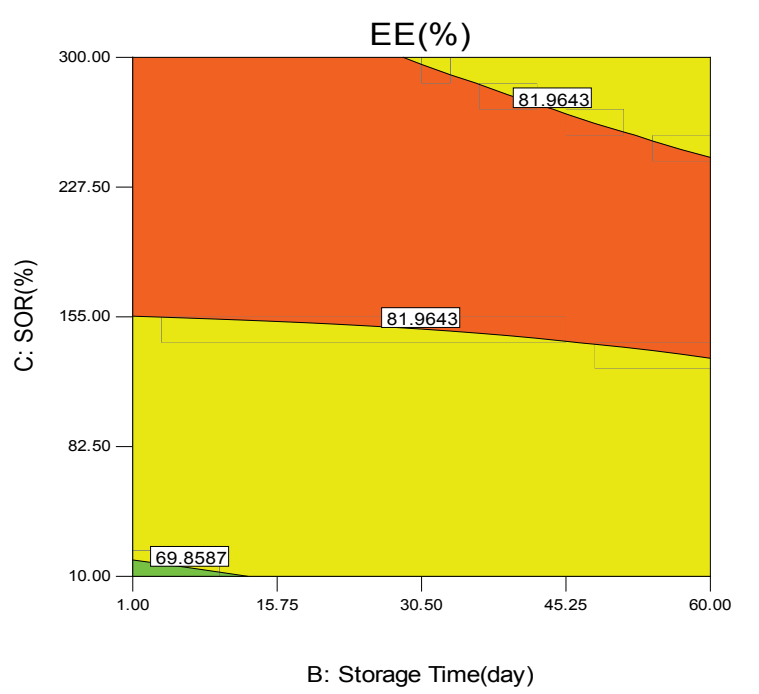

Figure 5: Contour plots of encapsulation efficiency versus omega $3(\%)$, SOR (\%) and storage time. 


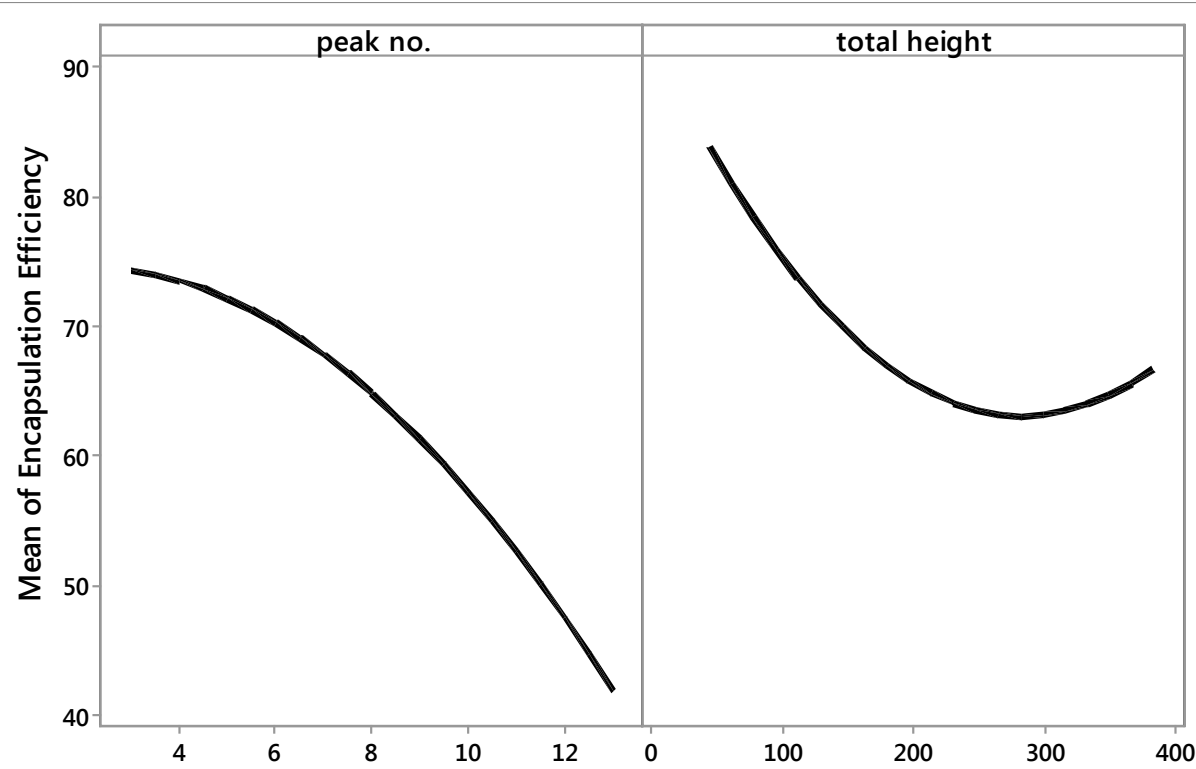

Figure 6: Main affect plot of encapsulation efficiency versus total peak number and total peak height.

$$
D=\left(d_{1}^{r 1} \times d_{2}^{r 2} \times \ldots d_{n}^{r n}\right) \sum^{\frac{1}{r i}}=\left(\prod_{i=1}^{n} d_{i}^{r i}\right)^{\frac{1}{\sum^{r i}}}
$$

Where $\mathrm{n}$ is the number of responses in the measure.

In this study the combined desirability function was used to estimate the condition that emulsion had the best release of volatile compounds (essential oils) and best encapsulation efficiency and the best omega 3 percent, surfactant-to-oil ratio (SOR\%), surfactant type and storage time.

Figure 7 show the desirability functions for factors and responses. According to the Figure 7 combined desirability function was calculated (0.944) and the optimum condition was calculated as: Omega 3(\%); 25, Storage Time (day); 60, SOR (\%); 193.33 and Surfactant type; T80 where the total peak number is 3 , total peak area is 407 , total peak height is 77 and encapsulation efficiency is $75 \%$. The mentioned values were selected as optimum values for providing emmulsion that has the best release.

\section{Conclusions}

New emulsion based on Mentha longifolia Essential oil loaded with omega 3 fatty acids was provided in the present work. The effects of omega 3 percent, surfactant-to-oil ratio (SOR\%), surfactant type (TWEEN 20,80 and caseinate sodium) and storage time (as independent variables) on the encapsulation efficiency and chromatographic characteristics (power of release) were studied. Extraction and determination of released essential oils from emulsion were done by HS-SPME/GC-FID method. The PANI nano fiber was used as an extraction solid phase. The effect of studied factors on the encapsulation efficiency and power of release was done based on the CCD. Desirability function was used for determination of optimum condition. Results showed that all studied four factors affected the 
Citation: Faraji N, Pirsa S, Alizadeh M, Almasi H (2018) Optimizing Production of Mentha longifolia Essential Oil Emulsion Loaded with Omega 3 Fatty Acids by Nano-Fiber/Gas Chromatography. J Bioanal Biomed 10: 30-39. doi:10.4172/1948-593X.1000201

encapsulation efficiency and gas chromatography characteristic. There is a relation between encapsulation efficiency and total peak area. The higher encapsulation efficiency showed the lower total peak number and area. The optimum condition for the best power of release was obtained as: Omega 3(\%); 25, Storage Time (day); 60, SOR (\%); 193.33 and Surfactant type; T80.

\section{Acknowledgment}

This work has been supported by grants from the Urmia University Research Council and Azin shoushtar company and the Iran National Science Foundation (INSF) is gratefully acknowledged. A very special thank to Mr. Sasan Ghanadan for his support throughout my research.

\section{Reference}

1. Komaiko J, McClements DJ (2016) Formation of Food-Grade Nanoemulsions Using Low-Energy Preparation Methods: A Review of Available Methods: comprehensive Reviews in Food Science and Food Safety 15: 331-352.

2. Walker RM, Decker EA, McClements DJ (2015) Physical andoxidative stability of fish oil nanoemulsions produced by spontaneous emulsification: effect of surfactant concentration and particle size. J Food Engineering 164:10-20.

3. Solans C, Izquierdo P, Nolla J, Azemar N, Garcia-Celma MJ (2005) Nanoemulsions. Curr Opin Colloid Interface Sci 10: 102-110.

4. Komaiko J, McClements DJ (2015) Low-energy formation of edible nanoemulsions by spontaneousemulsification: Factors influencing particle size. $\mathrm{J}$ of Food Engineering 146: 122-128.

5. Abbas S, Hayat K, Karangwa E, Bashari M, Zhang XM (2013) An overview of ultrasound-assisted food-grade nanoemulsions. Food Engineering Review 5 : 139-157.

6. Walker RM, Decker EA, McClements DJ (2015) Physical andoxidative stability of fish oil nanoemulsions produced by spontaneous emulsification: effect of surfactant concentration and particle size. J Food Engineering 164: 10-20

7. Rebecca M, Walker RM, Decker E, McClements DJ (2015) Physical and oxidative stability of fish oil nanoemulsions produced by spontaneous emulsification: Effect of surfactant concentration and particle size. J Food Engineering 164:10-20.

8. Hasler C, Bloch A, Thomson C (2004) Position of the American Dietetic Association: Functional foods. J American Dietetic Association 104: 814-826.

9. Hudson E (2010) Omega-3 fatty acids: The whole package. Nutraceutical Business \&Technology 6: 30-38.

10. Burt S (2004) Essential oils: their antibacterial properties and potential applications in foods review. International Journal of Food Microbiology 94: 223-253

11. Saeidi $Z$, babaahmadi $H$, Saeidi KA, Salehi $A$, Saleh Jouneghani $S$, et al. (2012) Essential oil content and composition of Menthalongifolia (L.) Hudson grown wild in Iran. J Medicinal Plants Res 6: 4522-4525.

12. Gulluce M, Sahin F, Sokmen M, Ozer H, Daferera D, et al. (2007) Antimicrobial and antioxidant properties of the essential oils and methanol extract from Menthalongifolia L. ssp. Iongifolia. Food Chem 103: 1449-1456.

13. Pawliszyn J (2009) Handbook of Solid Phase Microextraction, Chemical Industry Press.
14. Mezdour S, Desplanques S, Relkin P (2011) Effects of residual phospholipids on surface properties of a soft-refined sunflower oil: application to stabilization of sauce-type emulsions. Food Hydrocolloids 25: 613-619.

15. Komaiko J, Sastrosubroto A, McClements DJ (2015) Formation of Oil-inWater Emulsions from Natural Emulsifiers Using Spontaneous Emulsification: Sunflower Phospholipids. J Agriculture 63: 10078-10088.

16. Guttoff M, Saberi A, McClements DJ (2015) Formation of vitamin D nanoemulsion-based delivery systems by spontaneous emulsification: Factors affecting particle size and stability. Food Chemistry 171: 117-122.

17. Yating Z, Chen T, Shabbar A, Karangwa E, et al. (2014) The effect of soy protein structural modification on emulsion properties and oxidative stability of fish oil microcapsules. Colloids and Surfaces B: Biointerfaces 120: 63-70.

18. McClements DJ (2011) Edible nanoemulsions: Fabrication, properties, and functional performance. Soft Matter 7: 2297-2316.

19. McClements DJ, Li Y (2010) Structured emulsion-based delivery systems: Controlling the digestion and release of lipophilic food components. Advances in Colloid and Interface Science 159: 213-228.

20. Chantrapornchai W, Clydesdale FM, McClements DJ (2001) Influence of relative refractive index on optical properties of emulsions. Food Research International 34: 827-835.

21. Connell JJ (1990) Methods of assessing and selecting for quality. Control of fish quality (3rd ed.) London: Fishing News (Books) Ltd.

22. Pirsa S, Afshar A, Khani A, Allahverdi Pur A (2013) Fabrication of 1 1-Dimethylhydrazine Gas sensor Based on Nano Structure Conducting Polyaniline, J Sciences, Islamic Republic of Iran 24: 209-215.

23. Pirsa S, Alizadeh M, Ghahremannejad N (2016) Application of Nano-sized Poly N-phenyl Pyrrole Coated Polyester Fiber to Headspace Microextraction of Some Volatile Organic Compounds and Analysis by Gas chromatography. Curr Analyt Chem 12: 457- 464.

24. Alizadeh M, Pirsa S, Faraji N (2017) Determination of Lemon Juice Adulteration by Analysis of Gas Chromatography Profile of Volatile Organic Compounds Extracted with Nano-Sized Polyester-Polyaniline Fiber. Food Analytical Methods 10: 2092-2101.

25. Burt S (2004) Essential oils: their antibacterial properties and potential applications in foods a review. Int J Food Microbiol 9: 223-253.

26. Dias DO, Colombo M, Kelmann RG, De Souza TP, Bassani VL, et al (2012) Optimization of headspace solid-phase microextraction for analysis of caryophyllene in a nanoemulsion dosage form prepared with copaiba (Copaifera multijuga Hayne) oil. Analytica Chimica Acta 721: 79-84.

27. Dickinson E, Golding M (1997) Depletion flocculation of emulsions containing unadsorbed sodium caseinate. Food Hydrocollids 11: 13-18.

28. Reineccius GA (1989) Flavor encapsulation. Food Rev Int 5: 147-176.

29. Bylait E, Venskutonis PR, Mapdpierienë R (2001) Properties of caraway (Carum carvi L.) essential oil encapsulated into milk proteinbased matrices. Eur Food Res and Tech 212: 661-670.

30. Walker RM, Decker EA, McClements DJ (2015) Physical and oxidative stability of fish oil nanoemulsions produced by spontaneous emulsification: effect of surfactant concentration and particle size. J Food Engineering 164: 10-20.

31. Ton NMN, Tran TTT, Le VVM (2016) Microencapsulation of rambutan seed oil by spray-drying using different protein preparations. Int Food Res J 23: 123-128. 